younger children. The subject, is, however, too extensive to be entered on here.

For sound views on this and on other subjects connected with the public health, and for much valuable material on scrofulous affections generally, Mr. Phillips's work may be advantageously consulted, not only by the medical practitioner, but by the philanthropist and the legislator. It is no hurried production, hastily got up to serve a special purpose, but is evidently the result of much research, much observation and reflection, and years of labour well bestowed.

\section{ROYAL COLLEGE OF CHEMISTRY.}

ON THE USE OF THE MICROSCOPE AS AN AID IN CHEMICAL INQUIRY.

By John Davy, M.D., F.R.S., Lond. and Edin., Inspector-General of Army Hospitals.

(Read Wednesday, June 3rd,)

That the microscope may be an important aid to the chemical inquirer, I believe will be readily admitted by all those who have made trial of it, if tolerably familiar with its use, and in the habit of employing a good instrument. This last condition is essential. To be eminently useful in research, an instrument of the best construction should be employed-an achromatic one, with a magnifying power of at least three hundred diameters.

Such an instrument may be considered as a new power to the chemist ; making clear what was obscure; allowing him to distinguish by sight what, without such aid, he could determine only by complicated processes of analysis; enailing him to distinguish in a mixture of animal and vegetable substances various tissues and forms, and often in an instant, satisfy himself of their nature; and equally so to satisfy himself by simple inspection, whether in the preparation of chenical substances, either by sublimation or precipitation, they are pure and unmixed, or impure and mixed with saline matter or substances of a different kind thrown down or sublimed at the same time. Taking this view of the application of the microscope, I cannot but think that the time is not far distant when the philosophical chemist will require it as much as, and eren more frequently than, the balance; and that the one will be considered as essential to a laboratory of research as the other; and to the inquiring traveller, limited as to apparatus, more useful than any atlier single implement that can be mentioned hitherto attainable.

It may not be amiss to give a few examples for the purpose of illustration, making a selection from instances which have come under my own observation, some of which may be new.

Preparatory to entering on a chemical examination, it is a desideratum to become generally acquainted with the nature of the subject of it. Such preliminary information, the microscope is adiuirably fitted to afford.

It is a disputed point whether those peculiar, and, in many repects, singular birds, - the humming-birds, feed on insects or the sweet juices of flowers; some naturalists maintaining that they live exclusively on the one, others that they live exclusively on the other. By repeated observation-first microscopical, afterwards chemical, made on the contents of their minute stomachs, I have ascertained that insects are the solid food, and that the sweet juice of the nectary of flowers is the ordinary drink of these birds. The tongue of the humming-bird, projectile and bifid, is peculiarly fitted for taking insects, and when moist with a honied viscid lure, its power is even increased. In every stomach of this bird that I have examined I have detected with the microscope parts of insects, and sonetimes entire and living ones; and I have found their remains also in the lower intestine.

Another instance may be given from the urinary excrement of insects. In the mujority of cases in which I have examined this excrementitious matter, I have found it to be principally the lithate of ammonia, commonly in the form of granules, little exceeding in size the blood-corpuscles of man. In one instance however, - that of the excrement of a small night moth, subjecting it first to microscopical examinations, there were observed, mixed with the granules, well-formed crystals, resembling those of lithic acid, and which were proved to be of lithic acid by their chemical qualities, testing them chemically, and observing the results with the same power, for they were far too minute even to be seen with the naked eye.

Soils, sands, marls, afford other good examples of the use of the microscope as a preliminary to chemical examination.

Amongst the valuable deposits in the island of Barbadoes, distinguished for its extraordinary fertility, which it owes mainly to the nature of its soils, are beds of calcareous inarl. Under the microscope, this marl appears to be almost homogeneous, except that amongst the molecules of which it is composed, minute crystals are to be seen-short slender prisms, as of phosphate of lime; and chemically examined, it is found to contain phosphate of lime, its chief ingredient being the carbonate, with a trace of silica.

The fertile soils of this very fertile island have been supposed to be deficient in this last-mentioned substance; when subjected, however, to the microscope, the opinion is shown to be erroneous. In most of them silica is found in abundance, either in the form of fine quartz sand, bearing marks of being water worn, or in excessively minute angular fragments, probably of volcanic origin, or as the petrifying matter of infusoria; and chemical examination confirms this, proving, in addition, that silica is largely present in combination with alumina.

The sands of Barbadoes vary much in their nature, according to the situation in which they are found. The sea sand, from two-thirds of the shore constituting the circumference of the island, consists of comminuted shells, water-worn, with very little siliceous or other matters, forming a valuable material for the purposes of agriculture, although hitherto little used. From the remaining one-third of the shore, viz., from the north-east coast, the sand is a mixture of quartz, in water-worn grains, and of comminuted shells, the former preponderating. The shell sand corresponds to one kind of geological formation, the siliceous to another; the one peculiar to that part of the island, the greater portion of it consisting of ealcareons 
deposits, abounding in marine organic remains, whilst the siliceous sand corresponds to the smaller portion, formed of totally different deposits, partly clualk containing silicated infusoria, partly, and in larger proportion, of clay, sand, and gravel, more or less cohering, with which beds of coal are intermixed, the former seemingly the detritus of primitive and transitions rocks. Under the microscope, using a low power, the appearance of these two kinds of sand is distinctive. The shell sand is merely diaphanous, whilst the quartz sand is transparent, not to mention other peculiarities; and in mixture, the grains of each are most easily distinguished; so that even without chemical examination, on mere inspection, it may at once be pronounced which ingredient is in largest proportion. The sane decision from the like inspection muy be confidently made on some of the sands at a distance from the coast, which consist almost entirely of siliceous matter, without any traces of comminuted shells; and, in each instance, chemical examination is found to be confirmatory of the microscopical.

I shall pass now to some instances of a different kind. The unaided vision, as it is well known, cannot distinguish with sufficient exactness, precipitates of different substances by their appearance, when they are colourless, as those of the different earths, whether thrown down in the state of hydrate, or in combination with an acid. But, calling in the aid of the microscope, the distinction can often be made without difficulty; and, if not at once, it can be made with little trouble by the addition of an acid, of one the combinations of which, with different earths, under the microscope, have appearances that are characteristic of them.

Alumina and phosphate of lime,-the one an almost universal ingredient of soils, the other a rare ingredient, excepting in an exceedingly minute quantity, are, as is well known, both precipitated from solution in acid by ammonia. To determine which constitutes the precipitate, so important in relation to agricultural purposes, is a difficult matter, employing merely chemical means as tests, unless in a well appointed laboratory; but with the aid of the microscupe the difficulty vanishes. Seen with it, the precipitate of alumina, owing to its excessive subtility, and the low refractive power of its particles, has a hyaloid appearance, while the other has a very fine granular aspect. The addition of a drop of dilute sulphuric acid will make the appearances even nore distinct. If the precipitate is entirely aluminous, it will have a glacial appearance, and on evaporation to dryness, this appearance will be retained, the crystallizations formed being not unlike those of ice in their general character; whilst, if the precipitate is of phosphate of lime, immediately on admixture with the acid, if properly proportioned needle crystals will be seen to be formed, short slender prisms, and on evaporation the same crystals will appear in increased quantity, mixed with some delicate rhomboidal plates. In the instances of mixed precipitates by ammonia, of alumina and phosphate of lime, according as the one or the other predominates, will be the proportion in which the one or other aspect will be imparted to the mixture; and should phosphate of magnesia be present in admixture with alumina and phesphate of lime; it may easily be detected under the microscope ; before the addition of the acid its well-marked crystals will be seen, which, after that addition, will disappear.

As my.object is chiefly to draw attention to the application of the microscope as an aid to chemical research, the instances adduced, I trust, will be considered sufficient in the way of illustration; very many more might be given, but they would be out of place on this occasion. Were they minutely detailed, they would be tedious; and were they only briefly adverted to, practically they would be useless. The subject, to have justice done to it, would require a distinct treatise, founded on laborious research, and giving the results of such research, and it is one, of which it may confidently be predicated, that it would amply repay whatever time, whatever labour, might be expended on the undertaking.

In conclusion, this, it appears to me, may justly be said in commendation of the microscope, in all its applications, - that its tendency is equally to facilitate and increase accuracy of observation, and hence to remove vagueness and give precision of views, and at the same time to add wonderfully to the interest of inquiry, and to extend its sphere,-in this respect, having an influence in relation to subjects for chemical research resembling that of the most powerful telescopes in relation to the objects of astronomical research. Both conduce, the one hardly less than the other, by the phenomena they display, to excite in the mind of the philosophical inquirer, feelings of admiration, of awe, and of humility.

Barbadoes, January 19th, 1846.

\section{POISONING OF CHILDREN AT RUNCORN, BY ARSENIC.}

The following is the case of poisoning by arsenic, with the view of obtaining money from a Burial Society, alluded to in a recent number :-

The parents of the children, Joseph Pimlet, a ship carpenter, and Mary his wife, both considered to be respectablecharacters, took up their residence in Runcorn about seren or eight montbs ago, the husband at that time being a member of the Weaverham Friendly Society, which allows a small sum for funeral expenses on the death of a member, or any portion of his family. About the same period the children were entered as members of the Liverpool Victoria Legal Burial Society-a society which collects subscribtions of one penny per week for persons above five years old, and, in case of death, pays $\mathscr{E 5}$ at the expiration of twentyfour weeks' payment as funeral money; and one halfpenny per week under five years, and $\notin 2.10$ s. as funeral money. On the 6 th of March last, James Pimlet, a boy only ten months old, died, and there being some circumstances connected with his death which required an investigation, an inquest was held before Henry Churton, Esq., the county coroner, and on the evidence of the mother, a verdict of "found dead" was returned. On the 16 th of the same month, another child, Richard Pimlet, aged four years and six months, was taken ill. That child died on the 21 st and was buried, at the request of the father, under the coffin of the former. On Monday, the 27th of April, a third child, named Thomas Pimlet, about three years old, was taken ill, and attended by Mr. Edward Pye, 